\title{
DESIGN OF A NOVEL PHOTOELECTROCHEMICAL REACTOR FOR HYDROGEN PRODUCTION
}

\author{
FRANCIS N. NJOKA ${ }^{1}$, MAHMOUD A. AHMED ${ }^{1} \&$ SHINICHI OOKAWARA ${ }^{1,2}$ \\ ${ }^{1}$ Department of Energy Resources Engineering, Egypt-Japan University of Science and Technology, Egypt \\ ${ }^{2}$ Department of Chemical Science and Engineering, Tokyo Institute of Technology, Japan
}

\begin{abstract}
Photoelectrochemical hydrogen production is one promising way of producing hydrogen without emitting carbon dioxide into the atmosphere. Many semiconductor materials have been investigated over the past four decades although with huge financial constraints on experimental work to many research groups hindering faster research progress. In this paper, a numerical approach characterising the transport phenomena including reaction kinetics at the semiconductor-electrolyte interface is presented to facilitate a better understanding of the reactor with the aim of minimising the associated cost implications. The input photocurrent density is empirically evaluated from the standard reference solar spectra ASTM G173-03 using hematite as the semiconductor material of interest combined with other potential photoelectrodes. Charge transport and electrochemical kinetics in the two electrolyte chambers of a 2-D photoelectrochemical reactor model are simulated using Nernst Planck's and Butler Volmer equations respectively. Pure water ( $\mathrm{pH}$ neutral) is used as the electrolyte in the model. An ionpermeable membrane is also included in the simulations to isolate the reaction products which would otherwise result in product losses and pose danger under normal operations of the reactor. Despite the slow dissociation rate of water, progress in dissociation and the proton movement from the anolyte to the catholyte were clearly noticed. The evolution of hydrogen and oxygen from the cathode and anode surfaces respectively are also reported. Gas concentration seem to appear close to the electrode surfaces where the reactions occur with the high concentration band progressively widening with the reactor height. Results also show that the ratio of increment in hydrogen concentration doubled that of oxygen which affirms the equilibrium reaction of water splitting. Increase in the photocurrent density also results in increased gas production. These results provide an impetus for further investigations on the behaviour of the reactor to inform future research work.
\end{abstract}

Keywords: electrokinetics, practical PEC reactor design, simulation, species transport.

\section{INTRODUCTION}

Dwindling conventional energy resource supplies and the persistent intermittency and storage limitations associated with renewable energy systems continue to push for the development of new and more sustainable energy solutions for the future. Production of hydrogen by water splitting using the free energy of the sun is considered one such a noble idea. This approach is considered attractive as besides averting the carbon dioxide emission problems to the atmosphere, both water and solar energy are abundant resources hence sustainable. Similar to conventional water electrolysis (using electricity), photoelectrochemical (PEC) water splitting only replaces electricity with solar energy as a driving force acting on a semiconductor material. Due to the nature of the driving force and the semiconductor material responsiveness however, the current densities and the rate of hydrogen production are lower compared to conventional electrolysis.

In a PEC cell, water is split into hydrogen and oxygen when a suitable semiconductor material is illuminated by a light source. Where an n-type semiconductor (photoanode) is used for instance, the excited electrons in the valence band get energized and move to the conduction band creating electron-hole pairs [1]. These electron-hole pairs migrate in opposite directions to the electrode surface. The created holes in the valence band oxidise the water molecule into oxygen and hydrogen ions (protons). The generated electrons on the 


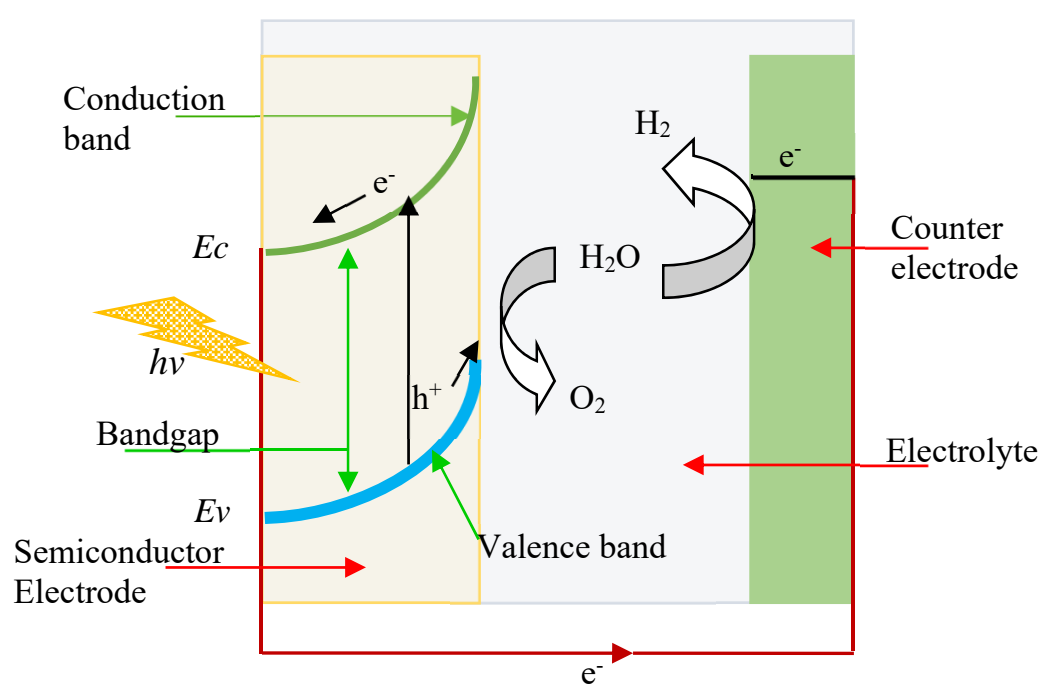

Figure 1: Operating principle of a PEC cell based on an n-type photoelectrode.

other hand migrate through the electrode and via the ohmic contact, to the counter-electrode (the cathode). The hydrogen ions formed in the electrolyte diffuse through the bulk electrolyte and link up with the electrons where they (ions) get reduced to hydrogen gas as shown in Fig. 1 where Ec, Ev and $h v$ represents conduction band, valence band and photon energy respectively.

The photoelectrode's electron-hole pairs in actual sense act as a pathway/link through which the water oxidation electrons migrate through. Therefore, the structure of the photoelectrode and the counter electrode is not altered. Under neutral conditions, the associated reactions at the electrodes (anode and cathode) and the overall reaction can be expressed as follows:

$$
\begin{gathered}
\text { Dissociation....... } \mathrm{H}_{2} \mathrm{O} \rightarrow \mathrm{OH}^{-}+\mathrm{H}^{+} \\
\text {Anode....... } 2 \mathrm{OH}^{-} \rightarrow \mathrm{H}_{2} \mathrm{O}+\frac{1}{2} \mathrm{O}_{2}+2 e^{-} \ldots . .\left(\mathrm{E}^{0}=0.81 \mathrm{~V}\right) \\
\text { Cathode........ } 2 \mathrm{H}^{+}+2 e^{-} \rightarrow \mathrm{H}_{2} \ldots \ldots . .\left(\mathrm{E}^{0}=-0.42 \mathrm{~V}\right) \\
\text { Overall........ } \mathrm{H}_{2} \mathrm{O} \rightarrow \frac{1}{2} \mathrm{O}_{2}+\mathrm{H}_{2} \ldots \ldots \ldots(\mathrm{E}=1.23 \mathrm{~V}) .
\end{gathered}
$$

However due to the low conductivity of water, most PEC reactors work under either acidic or alkaline conditions and the same reactions can as well be expressed as shown in eqns (5)-(7) and eqns (8)-(10) in acidic or alkaline conditions respectively

Acidic conditions;

$$
\begin{gathered}
\text { Anode..... } \mathrm{H}_{2} \mathrm{O} \rightarrow 2 \mathrm{H}^{+}+\frac{1}{2} \mathrm{O}_{2}+2 e^{-} \ldots \ldots . .\left(\mathrm{E}^{0}=1.23 \mathrm{~V}\right) \\
\text { Cathode........ } 2 \mathrm{H}^{+}+2 e^{-} \rightarrow \mathrm{H}_{2} \ldots \ldots .\left(\mathrm{E}^{0}=0 \mathrm{~V}\right)
\end{gathered}
$$




$$
\text { Overall......... } \mathrm{H}_{2} \mathrm{O} \rightarrow \frac{1}{2} \mathrm{O}_{2}+\mathrm{H}_{2} \ldots \ldots \ldots(\mathrm{E}=1.23 \mathrm{~V})
$$

Alkaline conditions;

$$
\begin{gathered}
\text { Anode........ } 2 \mathrm{OH}^{-} \rightarrow \mathrm{H}_{2} \mathrm{O}+\frac{1}{2} \mathrm{O}_{2}+2 e^{-} \ldots \ldots .\left(\mathrm{E}^{0}=0.40 \mathrm{~V}\right) \\
\text { Cathode..... } 2 \mathrm{H}_{2} \mathrm{O}+2 e^{-} \rightarrow 2 \mathrm{OH}^{-}+\mathrm{H}_{2} \ldots \ldots \ldots\left(\mathrm{E}^{0}=-0.83 \mathrm{~V}\right) \\
\text { Overall.......... } \mathrm{H}_{2} \mathrm{O} \rightarrow \frac{1}{2} \mathrm{O}_{2}+\mathrm{H}_{2} \ldots \ldots \ldots(\mathrm{E}=1.23 \mathrm{~V}) .
\end{gathered}
$$

Ideally, the minimum photon energy (or the net work done) required to decompose water into oxygen and hydrogen is $1.23 \mathrm{eV}$. In other words, unlike in a hydrogen-oxygen fuel cell (galvanic cell) where the two gases react spontaneously generating electricity and heat [2], water decomposition in turn is an endothermic process requiring a minimum external energy equivalent to $1.23 \mathrm{eV}$. This is equated to change in Gibb's free energy $\Delta \mathrm{G}^{\circ}=+237.2 \mathrm{~kJ} / \mathrm{mol}$ under standard conditions for an open cell where $\mathrm{P}, \mathrm{T}=$ constant [3]. The change in Gibb's free energy can as well be expressed in terms of electrical energy from, $\Delta \mathrm{G}^{\mathrm{o}}=-\mathrm{nFE}$, where, $\mathrm{n}$ is the number of electrons, $\mathrm{F}$ is the Faraday's constant $(96,485 \mathrm{C} / \mathrm{mol})$ and $\mathrm{E}$ is the ideal potential difference which translates to an equivalent of $1.23 \mathrm{~V} \mathrm{[4],} \mathrm{also} \mathrm{displayed} \mathrm{in} \mathrm{eqns} \mathrm{(4),}$ (7) and (10). Thermodynamically however, the process requires slightly more input energy to overcome the associated high entropies. As such, a minimum voltage of $1.48 \mathrm{~V}$ based on enthalpy change $\left(\Delta \mathrm{H}^{\circ}=285.8 \mathrm{~kJ} / \mathrm{mol}\right)$ at standard conditions of 1 bar and $25^{\circ} \mathrm{C}$ would be required.

In the past four decades, considerable achievements have been made on the development of efficient photoactive materials though with marginal practical efficiency achievements so far. Limitations are mainly attributed to large bandgaps for potential semiconductor materials, unfavourable band-edge positioning with respect to redox potential of water, material stability in electrolyte conditions, electron-hole recombination's at the semiconductor-electrolyte interface (SEI) among others. A lot of previous work, mainly based on experimental findings, have shown that there are quite a variety of semiconductor materials that can be explored for water splitting. Generally, there are two broad categories of photoelectrode materials that offer some promise in solar water splitting for hydrogen production namely; the metal oxides and non-oxide (mainly conventional PV materials) semiconductors [5], [6]. Whereas non-metal oxide materials such as crystalline silicon ( $\mathrm{Si}$ ), indium phosphate (InP), gallium phosphate $(\mathrm{GaP})$, gallium indium phosphate $\left(\mathrm{GaInP}_{2}\right)$, cadmium selenide (CdSe), amorphous silicon, etc., offer high efficiencies due to their narrow bandgaps, they suffer from photochemical corrosion under light illumination [7].

Among the vastly studied metal oxide semiconductors on the other hand include, titanium dioxide $\left(\mathrm{TiO}_{2}\right)$, zinc oxide $(\mathrm{ZnO})$, hematite $\left(\mathrm{a}-\mathrm{Fe}_{2} \mathrm{O}_{3}\right)$, tungsten trioxide $\left(\mathrm{WO}_{3}\right)$, strontium titanate $\left(\mathrm{SrTiO}_{3}\right)$, potassium tantalate $\left(\mathrm{KTaO}_{3}\right)$, and many others [8]. $\mathrm{TiO}_{2}$ having been studied for the longest time is highly handicapped due to its high bandgap (3.0-3.2eV) and as such, only absorbs UV light which is only 4\% of solar irradiance [4], [5], [9], [10]. This results in very low efficiencies. $\mathrm{ZnO}$ has higher electron mobility than $\mathrm{TiO}_{2}$ but also has a high bandgap and in fact performs poorer than $\mathrm{TiO}_{2}$. Both a- $\mathrm{Fe}_{2} \mathrm{O}_{3}$ and $\mathrm{WO}_{3}$ have slightly narrower bandgaps, are quite stable and also cheap. Theoretical solar-to-hydrogen (STH) efficiencies of $\sim 12.9-15.5 \%$ and $4.8 \%$ have been reported respectively [7], [11]. $\mathrm{Fe}_{2} \mathrm{O}_{3}$ despite showing some promise exhibits poor light absorption. $\mathrm{SrTiO}_{3}$ and $\mathrm{KTaO}_{3}$ despite 
having a large bandgap are the first single photoelectrodes to have been used for practical demonstrations without any electrical bias. Their efficiencies are however very low. There are also relatively newer materials which exhibit even better visible light responsiveness. Materials such as bismuth vanadate $\left(\mathrm{BiVO}_{4}\right)$, tantalum oxynitride $(\mathrm{TaON})$ and tantalum nitride $\left(\mathrm{Ta}_{3} \mathrm{~N}_{5}\right)$ have reported better theoretical solar-to-hydrogen (STH) efficiencies [7], [12].

Due to the very stringent requirements for water splitting, virtually no single semiconductor material has sufficiently managed to fulfil them. As a result, most PEC setups still require some additional electrical input (bias). To eliminating this external bias, several designs and assemblies of semiconductor materials have been developed. These includes overlaying different bandgap semiconductor materials over each other (tandem), series or parallel duo (2) photoelectrode arrangements or monoliths in an attempt to increase efficiency (the absorbed photocurrent) or adjusting band edges by use of catalysts. Most reported findings are however based on experimental work which exerts a huge financial constraint to the scope of what can be achieved. Theoretical and numerical characterization and evaluation of PEC reactors is very cost-effective and would come in handy under these situations. Numerical studies have hence, in the past few years drawn some attention and may play a very important role in complementing and/or informing experimental scanning of photoelectrodes in future research studies.

Nonetheless, a considerable amount of numerical work has already been demonstrated by several research groups albeit with many challenges. A very thorough theoretical background to PEC simulation and design work has been shown by Carver et al. [13]. Potential distribution across the electrode, electrode resistance analysis and improvement strategies, reactor fluid flow and bubble formation and saturation have also been explored [13]-[16]. An in-depth analysis of design considerations for both back-to-back series/tandem and side-by-side/parallel duo photoelectrodes has been displayed too [17]. Dumontier and Haussener have also given some insights into transport phenomena, effects of temperature and $\mathrm{pH}$ preconditioning [18]. The effects of temperature on PEC with solar concentration have been thoroughly explored by several researchers as well [19]-[23]. Ong et al. [19] and Park et al. [24], have also given some insightful studies on semiconductor modelling including electron-hole recombination losses at the SEI.

A rather more application-based view on the effects of irradiance and temperature and the associated yields has also been demonstrated [25]. A similar approach has also been demonstrated by Ronaszegi. et al [26], where the unabsorbed larger wavelengths are used for thermal applications. All these studies highlight some key and fundamental challenges that still face PEC technology yet giving very useful information that informs future developments. Our study sought to model a complete practical PEC reactor based on series type face-to-face metal oxide photoelectrodes at varying photocurrent densities. The kinetics at the photoelectrode-electrolyte interface, overall transport phenomena within the entire reactor and the associated potential drops are evaluated.

\section{THEORETICAL MODEL}

\subsection{Initial photocurrent}

A simple empirical calculation of the input photocurrent density based on the standard reference solar spectra ASTM G173-03 under air mass 1.5 was used. The reference spectra was normalised to correct for wavelength discrepancies before conversion of the wavelengthspecific power to photon flux. Hematite $\left(\mathrm{Fe}_{2} \mathrm{O}_{3}\right)$ with bandgap range of 1.9-2.2 was used as 
the principle photoelectrode material in conjunction with several other smaller bandgap semiconductors to estimate the photocurrent pairing after integration of the respective photocurrents. Results of this section are however not reported in this paper.

\subsection{Reactor potential distribution}

The potential drop across the reactor was addressed wholesomely with the total potential difference being expressed as;

$$
\phi^{\text {reactor }}=\phi^{\text {anode/solution }}+\phi^{\text {solution }}+\phi^{\text {membrane }}+\phi^{\text {cathode/solution }} \text {. }
$$

For both interfaces,

$$
\phi^{\text {interface }}=E^{\text {therm }}+\phi^{B B}+\eta,
$$

where, $E^{\text {therm }}=$ thermodynamic potential, $\phi^{B B}=$ potential loss due to band bending $\eta=$ overpotential at either anode or cathode side.

Thermodynamic potentials can be obtained from,

$$
E=E^{0}+A \cdot p H+B \cdot \log P_{g a s},
$$

where, $\mathrm{A}$ and $\mathrm{B}$ are additional constants and $P_{\text {gas }}$ is the partial pressure of the relevant gas $\left(\mathrm{H}_{2}\right.$ or $\left.\mathrm{O}_{2}\right)$. Where the reaction results in gas formation, $P_{\text {gas }}$ may be taken to be atmospheric pressure. Therefore, for both photoanode and photocathode, the thermodynamic terms were taken as;

$$
\begin{gathered}
E_{\mathrm{O}_{2}}=1.229(\mathrm{~V})-0.059 \cdot p H+0.0148 \cdot \log P_{\mathrm{O}_{2}} \\
E_{\mathrm{H}_{2}}=0(\mathrm{~V})-0.059 \cdot p H+0.0296 \cdot \log P_{\mathrm{H}_{2}} .
\end{gathered}
$$

This explains the differences noted in the potentials for water reaction equations displayed earlier for neutral, acidic and alkaline conditions.

\subsection{Charge transport}

Nernst-Planck's equation was used to evaluate the general charge transport by diffusion, migration and convection within the liquid electrolyte. The consumption or production from chemical reactions of species, the molar flux of species and electrolytic current (sum of charged species fluxes) were respectively given by eqns (16), (17) and (18);

$$
\begin{gathered}
R_{i}=\frac{\partial c_{i}}{\partial t}+\nabla \cdot\left(-D_{i} \nabla c_{i}-z_{i} u_{m, i} F c_{i} \nabla \phi_{l}\right)+u \cdot \nabla c_{i} \\
N_{i}=-D_{i} \nabla c_{i}-z_{i} u_{m, i} F c_{i} \nabla \phi_{l}+u c_{i} \\
i_{l}=F \sum_{i} z_{i}\left(-D_{i} \nabla c_{i}-z_{i} u_{m, i} F c_{i} \nabla \phi_{l}\right),
\end{gathered}
$$

where, $c_{i}$ is the species concentration $\left(\mathrm{mol} / \mathrm{m}^{3}\right), D_{i}$ is species diffusion coefficient $\left(\mathrm{m}^{2} / \mathrm{s}\right), z_{i}$ is the species charge number (dimensionless), $u_{m, i}$ is the ionic mobility of species $(\mathrm{mol} \cdot \mathrm{s} / \mathrm{kg}), \mathrm{F}$ is Faradays constant $(96,485 \mathrm{~kJ} / \mathrm{mol})$ and $\phi_{1}$ electrolyte potential (V). 


\subsection{Electrochemical kinetics}

The charge transfer current density across the reactor was evaluated using the famous Butler Volmer's equation for both the anolyte and catholyte sides of the reactor as shown in eqn (19).

$$
i=i_{0}\left\{\exp \left(\frac{\alpha_{a} F \eta}{R T}\right)-\exp \left(\frac{-\alpha_{c} F \eta}{R T}\right)\right\} .
$$

The values for $i_{0}$ are respective exchange current densities, $\alpha_{a}$ and $\alpha_{c}$ are anodic and cathodic charge transfer coefficients, $R$ is the universal gas constant $(\mathrm{J} / \mathrm{mol} \cdot \mathrm{K})$ and $T$ is the reactor temperature $(298 \mathrm{~K})$. The overpotential, $\eta$ at the interfaces was calculated from eqn (20) where $\beta$ is the Tafel coefficient and $g$ here represents either hydrogen or oxygen.

$$
\eta_{g}=-\beta_{g}^{-} \ln \left(\frac{i_{g}}{i_{0, g}}\right) \text {. }
$$

\subsection{Fluid flow}

A steady state, incompressible Newtonian flow was assumed for purposes of defining and characterising the behaviour of the fluid in all our simulations as per eqn (21) where $\rho$ is the fluid density, $u$ and $v$ represents the fluid velocity in $\mathrm{x}$ and y directions respectively.

$$
\frac{\partial(\rho u)}{\partial x}+\frac{\partial(\rho v)}{\partial y}=0
$$

The electrolyte flow through the entire reactor body was considered to be laminar exhibiting very low Reynold numbers. Entry flow velocity was estimated from the relationship between the fluid dynamic viscosity $\mu$, fluid density $\rho$, characteristic diameter $D$ and Reynolds number Re as shown in eqn (22).

$$
u=\frac{\mu \mathrm{Re}}{\rho D}, \operatorname{Re}<2300 \text {. }
$$

The general Navier-Stokes equations (conservation of momentum) were applied to characterise the fluid momentum in the reactor in the $x$ and $y$ directions as shown in eqns (23) and (24) respectively

$$
\begin{gathered}
u \frac{\partial(\rho u)}{\partial x}+v \frac{\partial(\rho u)}{\partial y}=\frac{\partial P}{\partial x}+\mu\left(\frac{\partial^{2} u}{\partial x^{2}}+\frac{\partial^{2} u}{\partial y^{2}}\right) \\
u \frac{\partial(\rho v)}{\partial x}+v \frac{\partial(\rho v)}{\partial y}=\frac{\partial P}{\partial y}+\mu\left(\frac{\partial^{2} v}{\partial x^{2}}+\frac{\partial^{2} v}{\partial y^{2}}\right)-\rho g \beta\left(T-T_{0}\right)
\end{gathered}
$$




\section{MODEL DESCRIPTION}

The two-dimensional model geometry was made up of five domains; two domains for both the electrodes (cathode and anode) and the electrolyte (catholyte and anolyte) and one for the membrane. The electrode thickness, usually composed of a transparent conducting oxide (TCO) coated with the semiconductor layer was ignored and only a thin semiconductor layer of $10 \mu \mathrm{m}$ was considered. A proton-permeable membrane, characteristic of Nafion 117 of thickness $125 \mu \mathrm{m}$ and bulk electrolyte fields of $4 \mathrm{~mm}$ were used for the preliminary analysis. The height of all the domains was maintained at $40 \mathrm{~mm}$ as shown in Fig. 2. A steady state study with current initialization was carried out using finite element numerical simulation model, COMSOL Multiphysics 5.2, to evaluate the behaviour of the PEC reactor. With all the domains being regular rectangles of varying thicknesses, a mapped mesh with comparable mesh size distributions was used to discretise the domains for better convergence.

Pure water ( $\mathrm{pH}$ neutral) was used as the electrolyte and fed from the inlets (bottom of the cell) at a constant flow rate in the y-direction. The flow was assumed to exhibit very low Reynold numbers $(\sim 100)$ and from eqn (22) and assuming a circular inlet with a diameter equal to the size of the electrolyte thickness, flowrate adjustments in the range of 0.0025 $0.005 \mathrm{~m} / \mathrm{s}$ were considered appropriate. From eqns (23) and (24), body forces were initially considered to influence momentum in the main direction of flow but were also ignored in the simulation as a single-phase flow model was executed. The electrolyte was assumed to dissociate in the bulk as per eqn (1) while the oxidation, eqn (2) and reduction, eqn (3) reactions took place at the interior surfaces of the semiconductor electrodes or SEI. All species, both neutral and charged were accounted for in the model with their corresponding reference inlet and initial concentrations being specified. Initial concentrations for hydrogen and oxygen were assumed to be their respective saturation concentrations in water [17]. A Danckwert's boundary condition was imposed at the inlets to preserve both the reactant flux and the continuity of reactants concentrations. Nernst Planks equation characterised both the ion fluxes and charge transport due to diffusion, migration and convection in the model.

The outer surface of the cathode was grounded and that of the anode was set under a constant photocurrent density as input flux. The full Butler-Volmer kinetics equation was applied on both SEIs. A film resistance of $10 \Omega / \mathrm{m}^{2}$ typical of Pt- or $\mathrm{RuO}_{2}$-coated photoelectrodes was applied at both SEIs. Owing to the fact that only protons crossed through the membrane and from conditions of electroneutrality, eqn (18) was reduced to eqn (25) at the membrane where $\sigma_{l}$ is membrane conductivity. 


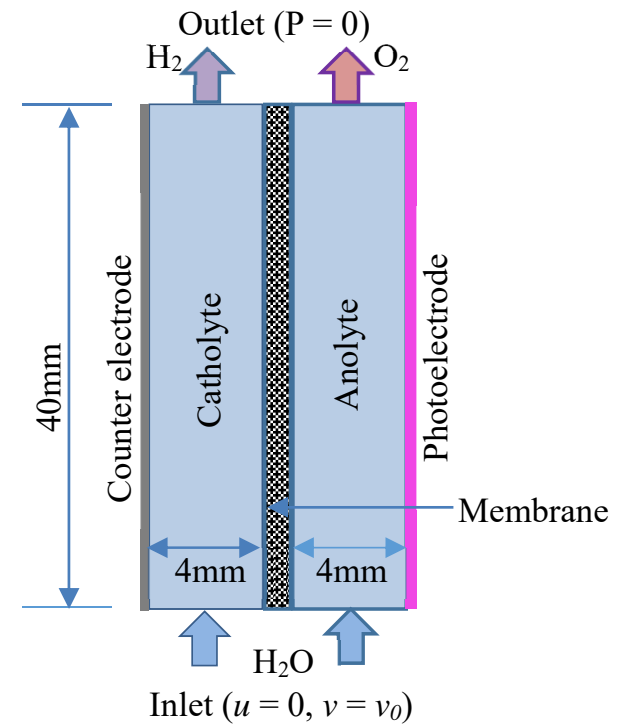

Figure 2: Physical model used in simulation.

Table 1: Key model parameters used in the simulation.

\begin{tabular}{|c|c|c|c|c|c|}
\hline \multicolumn{2}{|l|}{ Parameter } & Value & \multicolumn{2}{|l|}{ Parameter } & Value \\
\hline \multirow{5}{*}{$\begin{array}{l}\text { Diffusion } \\
\text { coefficients }\end{array}$} & $\mathrm{H}_{2}$ & $5.11 \times 10^{-8} \mathrm{~m}^{2} / \mathrm{s}$ & Initial & $\mathrm{H}_{2}$ & $0.78 \mathrm{mols} / \mathrm{m}^{3}$ \\
\hline & $\mathrm{O}_{2}$ & $2.42 \times 10^{-8} \mathrm{~m}^{2} / \mathrm{s}$ & \multirow{4}{*}{ concentrations } & $\mathrm{O}_{2}$ & $1.23 \mathrm{mols} / \mathrm{m}^{3}$ \\
\hline & $\mathrm{H}_{2} \mathrm{O}$ & $2.299 \times 10^{-4} \mathrm{~m}^{2} / \mathrm{s}$ & & $\mathrm{H}_{2} \mathrm{O}$ & $54000 \mathrm{mols} / \mathrm{m}^{3}$ \\
\hline & $\mathrm{H}^{+}$ & $9.312 \times 10^{-8} \mathrm{~m}^{2} / \mathrm{s}$ & & $\mathrm{H}^{+}$ & $1000 \mathrm{mols} / \mathrm{m}^{3}$ \\
\hline & $\mathrm{OH}^{-}$ & $5.0 \times 10^{-8} \mathrm{~m}^{2} / \mathrm{s}$ & & $\mathrm{OH}^{-}$ & $1000 \mathrm{mols} / \mathrm{m}^{3}$ \\
\hline $\begin{array}{l}\text { Mem diffusion } \\
\text { coefficient }\end{array}$ & $\mathrm{H}^{+}$ & $2.4 \times 10^{-8} \mathrm{~m}^{2} / \mathrm{s}$ & $\begin{array}{l}\text { Membrane } \\
\text { conductivity }\end{array}$ & $\sigma_{\mathrm{m}}$ & $10 \mathrm{~S} / \mathrm{m}$ \\
\hline \multirow[t]{2}{*}{$\begin{array}{l}\text { Exchange } \\
\text { current densities }\end{array}$} & $\mathrm{i}_{0, \mathrm{H} 2}$ & $8.7 \times 10^{-5} \mathrm{~A} / \mathrm{cm}^{2}$ & $\begin{array}{l}\text { Electrode } \\
\text { conductivity }\end{array}$ & $\sigma_{\mathrm{s}}$ & $66.7 \mathrm{~S} / \mathrm{m}$ \\
\hline & $\mathrm{i}_{0,02}$ & $2 \times 10^{-13} \mathrm{~A} / \mathrm{cm}^{2}$ & $\begin{array}{l}\text { Dissociation } \\
\text { constant }\end{array}$ & $\mathrm{kd}$ & $\begin{array}{l}9.534 \times 10^{-4} \\
\mathrm{~mol} / \mathrm{m}^{3} . \mathrm{s}\end{array}$ \\
\hline Transfer & OER & $\alpha_{\mathrm{a}}=0.85 \alpha_{\mathrm{c}}=0.1$ & Tafel & $\beta_{\mathrm{H} 2}$ & $19.2 / \mathrm{V}$ \\
\hline coefficients & HER & $\alpha_{a}=0.5 \alpha_{c}=0.5$ & coefficients & $\beta_{\mathrm{O} 2}$ & $24 / \mathrm{V}$ \\
\hline
\end{tabular}

A mix of Dirichlet and Neumann boundary conditions were imposed at the membrane to assure continuity of the electrolyte potential in the three liquid domains as well as the diffusion of the protons. Here, the normal electrolyte current density was assumed to be equal to that of the membrane and from Faraday's law, the proton flux across the membrane was also assumed to be proportional to the current as shown in eqns (26) and (27) respectively. Zero flux was considered for all non-permeable ions. The potentials were then related to the proton concentration by eqn (28), where $a_{i, m}$ is the permeable ion activity in the membrane and $a_{i, e}$ is the permeable ion activity in the electrolyte. Nafion membrane exhibits a proton activity similar to common acids $(0.8-2.4)$ [27]. Since the membrane proton concentration was unknown, a proton activity of 1.1 was used 


$$
\begin{gathered}
i_{l}=-u_{m,+} F^{2} C_{+} \nabla \phi_{l}=\sigma_{l} \nabla \phi_{l} \\
n \cdot i_{l, e}=n \cdot i_{l, m} \\
n \cdot N_{+, e}=n \cdot \frac{i_{l, m}}{F} \\
\phi_{l, m}=\phi_{l, e}+\frac{R T}{F} \ln \left(\frac{a_{+, m}}{a_{+, e}}\right) .
\end{gathered}
$$

All through the model, species activities were assumed to be equal to their respective concentrations divided by $1000 \mathrm{~mol} / \mathrm{m}^{3}$. Key model parameters are shown in Table 1 .

\section{RESULTS AND DISCUSSION}

For purposes of model validation, a quick potential summation was done to check its validity. The reported potential $(2 \mathrm{~V})$ was within an appropriate range for the case of hematite.

Fig. 3(a) shows the dissociation of water into hydrogen and hydroxide ions. Water has a higher tendency to associate than dissociate and hence the dissociation is a bit sluggish as seen from the figure as well as from the low rate constant (kd) shown in Table 1. Fig. 3(b) shows the hydrogen ions concentration in both the anolyte (right) and catholyte (left) at half height of the reactor. The flow of the protons from the anolyte to the catholyte is indicated by the sharp drops and rise across the membrane. At the cathode, the reduction in proton concentration is due to consumption of the reactant while that on the right-hand side is due

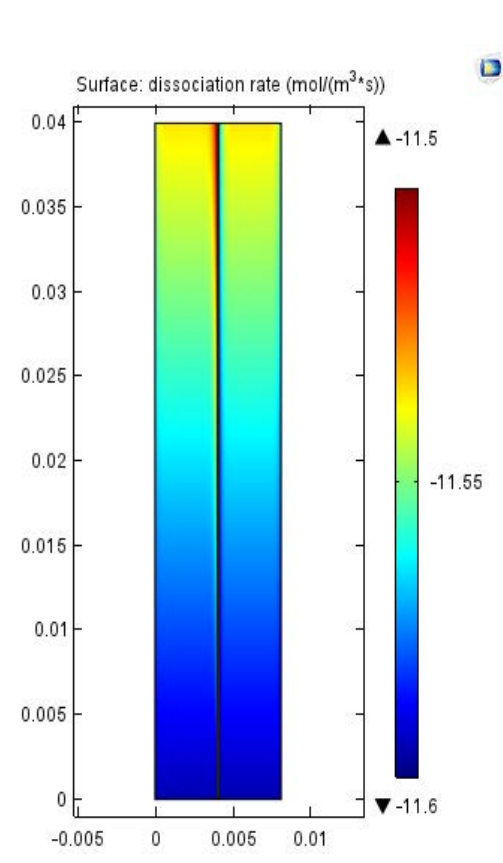

(a)

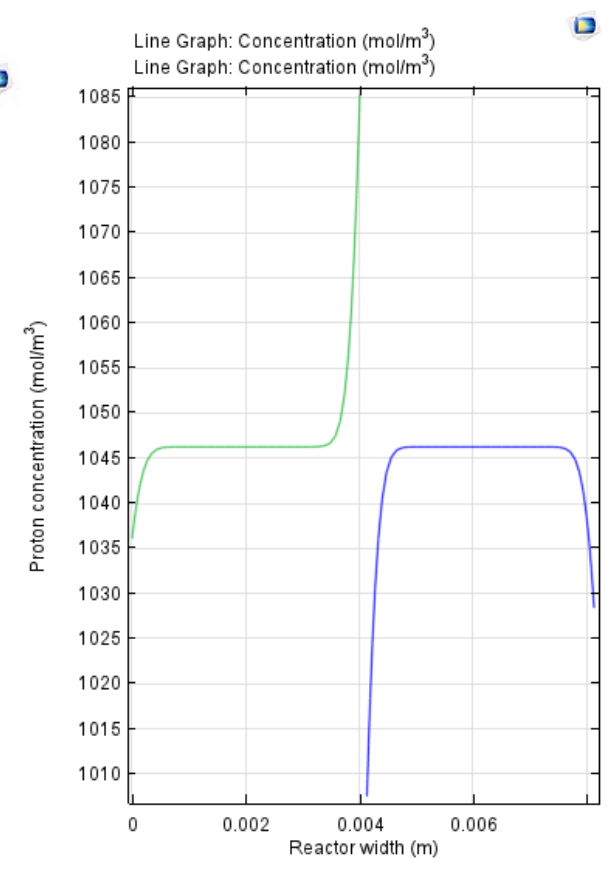

(b)

Figure 3: (a) Water dissociation in the bulk electrolyte; and (b) Proton concentrations in the electrolyte domains at half reactor height. 
to the fact that no hydrogen ions are expected near the anode as dissociation takes place in the bulk.

From the initial saturation concentrations of both hydrogen and oxygen, the concentrations are seen from Fig. 4 to sharply increase near the electrode surfaces where the reactions are presumed to be taking place. Most of the bulk electrolyte remains the same all through. The high concentration band also seems to widen and get more intense towards the outlet. Nearly the whole first quarter of the reactor shows marginal rise in concentration. This is probably an indication of the influence of fluid flow on the evolved gas which helps in clearing gas bubble accumulation on the electrode surface. The concentration ratio of hydrogen also rose to roughly double that of oxygen which correlates with the equilibrium reaction of water splitting. The amount of hydrogen or oxygen produced is proportional to the photocurrent densities on the photoelectrode surface. Empirical calculations of photocurrent densities from the standard solar spectra ASTM G173-03 showed that hematite would produce from about $63-110 \mathrm{~A} / \mathrm{m}^{3}$ when combined with other photoelectrodes.

Fig. 5 represents the concentration of hydrogen along the height of the reactor just $0.5 \mathrm{~mm}$ from the surface of the photocathode. These increments reflect the correlation between photocurrent density and the produced gas.

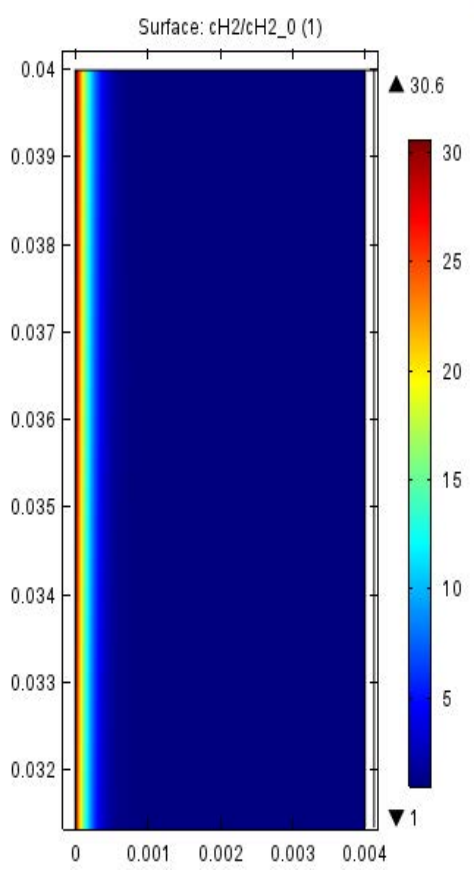

(a) $\mathrm{H}_{2}$ concentration.

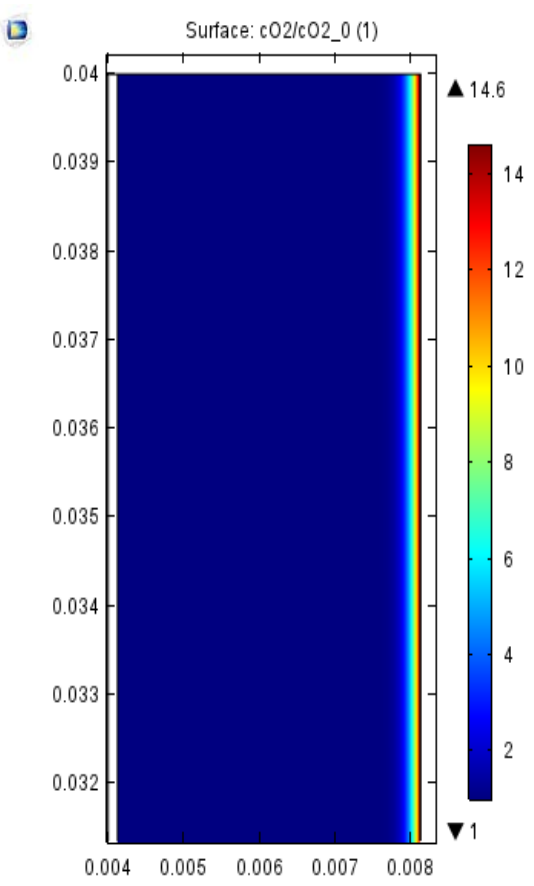

(b) $\mathrm{O}_{2}$ concentration.

Figure 4: Hydrogen and oxygen concentrations as a ratio of their initial concentrations at the upper half of the reactor. 


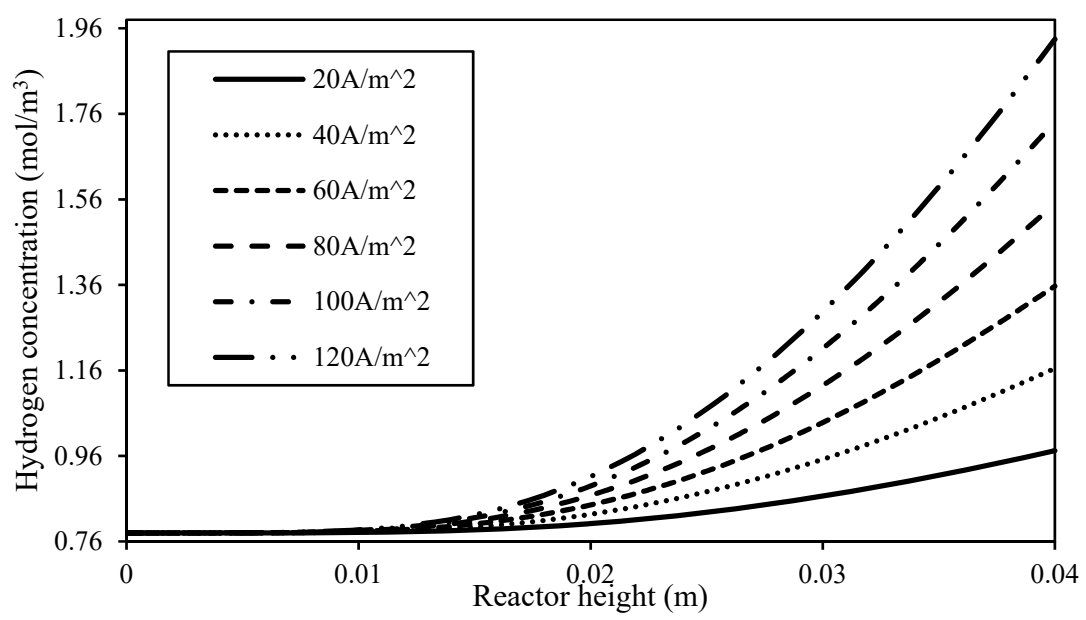

Figure 5: Hydrogen concentration along the height of the reactor $0.5 \mathrm{~mm}$ from the electrode surface at different current densities.

\section{CONCLUSION}

In conclusion, transport phenomena including electrochemical kinetics in the two electrolyte chambers of a 2-dimensional PEC reactor is numerically investigated. The ion-permeable membrane is also included in the simulations to isolate the reaction products which would otherwise result in product losses and pose danger under normal operations of the reactor. Despite the low dissociation rate of water, a positive dissociation and proton movement from the anolyte to the catholyte was reported. Evolution of hydrogen and oxygen from the cathode and anode surfaces was respectively reported. Gas concentration seem to appear close to the electrode surfaces where the reactions occur with the high concentration band progressively widening with the reactor height. Results also show the ratio of increment in hydrogen concentration ratio was twice that of oxygen which mimics the equilibrium reaction of water splitting. Increase in the photocurrent density also resulted in proportional increase in gas production. These results provide the basis for further interrogation of the reactor design to facilitate the development of an optimised reactor that could be adopted to practical field applications.

\section{REFERENCES}

[1] Liao, C.H., Huang, C.-W. \& Wu, J.C.S., Hydrogen Production from Semiconductorbased Photocatalysis via Water Splitting. Catalysts, 2(4), pp. 490-516, 2012.

[2] Revankar, S. \& Majumdar, P., Fuel cells: principles, design, and analysis. CRC Press, Taylor and Francis Group, Broken Sound Parkway, Boka Raton, New York, USA, 2014.

[3] Zoullias, E., Varkaraki, E., Lymberopoulos, N., Christodoulou, C. \& Karagiorgis, G., A Review of Water Electrolysis. TCJST, 4, pp. 41-71, 2004.

[4] Krol, R., Principles of Photoelectrochemical Cells. In Photoelectrochemical Hydrogen Production, eds. van de Krol, R. \& Grätzel, M. Boston, MA: Springer US, 102, pp. 13-67, 2012. 
[5] Minggu, L.J., Wan Daud, W.R. \& Kassim, M.B., An overview of photocells and photoreactors for photoelectrochemical water splitting. Int. J. Hydrog. Energy, 35(11), pp. 5233-5244, 2010.

[6] Bak, T., Nowotny, J., Rekas, M. \& Sorrell, C., Photo-electrochemical hydrogen generation from water using solar energy. Materials-related aspects. Int. J. Hydrog. Energy, 27(10), pp. 991-1022, 2002.

[7] Li, Z., Luo, W., Zhang, M., Feng, J. \& Zou, Z., Photoelectrochemical cells for solar hydrogen production: current state of promising photoelectrodes, methods to improve their properties, and outlook. Energy Env. Sci, 6(2), pp. 347-370, 2013.

[8] Sayama, K., Mixed Metal Oxide Photoelectrodes and Photocatalysts. In Photoelectrochemical Hydrogen Production, eds van de Krol, R. \& Grätzel, M., Boston, MA: Springer US, 102, pp. 157-172, 2012.

[9] Chen, J. et al., Recent progress in enhancing solar-to-hydrogen efficiency. J. Power Sources, 280, pp. 649-666, 2015.

[10] Pincella, F., Isozaki, K. \& Miki, K., A visible light-driven plasmonic photocatalyst. Light Sci. Appl., 3(1) p. 133, 2014.

[11] Dotan, H., Sivula, K., Grätzel, M., Rothschild, A. \& Warren, S.C., Probing the photoelectrochemical properties of hematite $(\alpha-\mathrm{Fe} 2 \mathrm{O} 3)$ electrodes using hydrogen peroxide as a hole scavenger. Energy Env. Sci, 4(3), pp. 958-964, 2011.

[12] Bhatt, M.D. \& Lee, J.S., Recent theoretical progress in the development of photoanode materials for solar water splitting photoelectrochemical cells. J Mater Chem A, 3(20), pp. 10632-10659, 2015.

[13] Carver, C., Ulissi, Z., Ong, C.K., Dennison, S., Kelsall, G.H. \& Hellgardt, K., Modelling and development of photoelectrochemical reactor for $\mathrm{H} 2$ production. Int. J. Hydrog. Energy, 37(3), pp. 2911-2923, 2012.

[14] Farivar, F., CFD simulation and development of an improved photoelectrochemical reactor for $\mathrm{H} 2$ production. Int. J. Hydrog. Energy, 41(2), pp. 882-888, 2016.

[15] Carver, C., Ulissi, Z., Ong, C.K., Dennison, S., Hellgardt, K. \& Kelsall, G.H., Modeling and Evaluation of a Photoelectrochemical Reactor for $\mathrm{H} 2$ Production. ECS Transactions, 28(26), pp. 103-117, 2010.

[16] Hankin, A., Kelsall, G., Ong, C.K. \& Petter, F., Photo-electrochemical production of hydrogen using solar energy. Chem. Eng. Trans., pp. 199-204, 2014.

[17] Haussener, S., Xiang, C., Spurgeon, J.M., Ardo, S., Lewis, N.S. \& Weber, A.Z., Modeling, simulation, and design criteria for photoelectrochemical water-splitting systems. Energy Environ. Sci., 5(12), p. 9922, 2012.

[18] Dumortier, M. \& Haussener, S. Design guidelines for concentrated photoelectrochemical water splitting devices based on energy and greenhouse gas yield ratios. Energy Env. Sci., 8(11), pp. 3069-3082, 2015.

[19] Ong, C.K., Dennison, S., Hellgardt, K. \& Kelsall, G., Evaluation and Modeling of a Photo-Electrochemical Reactor for Hydrogen Production Operating under High Photon Flux, pp. 11-19, 2011.

[20] Tembhurne, S., Dumortier, M. \& Haussener, S., Heat transfer modeling in integrated photoelectrochemical hydrogen generators using concentrated irradiation. In Proc. 15th Int. Heat Transf. Conf., Aug. 10-15, Kyoto, Japan, 2014.

[21] Tseng, C.L. et al., Numerical analysis of the solar reactor design for a photoelectrochemical hydrogen production system. Int. J. Hydrog. Energy, 37(17), pp. 13053-13059, 2012. 
[22] Qureshy, A. M., Ahmed, M. \& Dincer, I., Simulation of transport phenomena in a photo-electrochemical reactor for solar hydrogen production. Int. J. Hydrog. Energy, 41(19), pp. 8020-8031, 2016.

[23] Tseng C.-J. \& Tseng, C.-L., The reactor design for photoelectrochemical hydrogen production. Int. J. Hydrog. Energy, 36(11), pp. 6510-6518, 2011.

[24] Park, H.S., Ha, H.-W., Ruoff, R.S. \& Bard, A.J., On the improvement of photoelectrochemical performance and finite element analysis of reduced graphene oxide-BiVO4 composite electrodes. J. Electroanal. Chem., 716, pp. 8-15, 2014.

[25] Haussener, S., Hu, S., Xiang, C., Weber, A.Z. \& Lewis, N.S., Simulations of the irradiation and temperature dependence of the efficiency of tandem photoelectrochemical water-splitting systems. Energy Environ. Sci., 6(12), p. 3605, 2013.

[26] Ronaszegi, K., Brett, D.J. \& Fraga, E.S., System Modelling for Hybrid Solar Hydrogen Generation and Solar Heating Configurations for Domestic Application. In Renewable Energy in the Service of Mankind, Springer, I, pp. 123-131, 2015.

[27] Umeda, M., Sayama, K., Maruta, T. \& Inoue, M., Proton activity of Nafion 117 membrane measured from potential difference of hydrogen electrodes. Ionics, 19(4), pp. 623-627, 2013. 